\title{
Heading a consortium
}

In recent years, major research consortiums spanning academia, industry and government have been founded to address key challenges in basic and translational research. This month we feature two scientists with key roles in fostering such collaborative, interdisciplinary research activities.

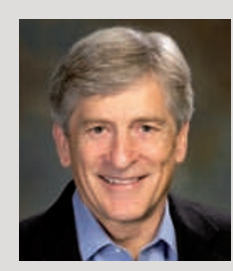

James Paulson, Ph.D. Principal Investigator and Director of the Consortium for Functional Glycomics, The Scripps Research Institute, California, USA.

The Consortium for Functional Glycomics (CFG; http://www.functionalglycomics.org) was set up in 2001 with a 'glue grant' from the National Institute of General Medical Sciences (NIGMS). "These large-scale grants are intended to glue together the grant-funded research of a group of investigators around a large biomedical research problem. Our project seeks to understand the roles of glycan-binding proteins in biology and to define the paradigms by which glycan-binding proteins mediate cell communication," says James Paulson, Director of the CFG

Today, the CFG comprises a multidisciplinary group of more than 500 scientists from $\sim 170$ institutions worldwide. As Director, Paulson's role is to organize this collaborative research effort and to provide leadership in working towards the overall goal. "This involves chairing a 2-hour Steering Committee meeting every other week, and holding a 2-day participating investigator meeting each year. In the past couple of years, we have also held 3-4 workshops in the US and Europe each year," he explains.

Paulson views his career - leading to and including his current position - in three periods following 4 years of postdoctoral work at Duke University, North Carolina, USA, with Dr Robert Hill. "The first was 12 years in the Department of Biological Chemistry at the UCLA [University of California, Los Angeles] School of Medicine where I went through the academic ranks from assistant to full professor," he says. The second period lasted for 10 years as a senior biotechnology executive, where he managed the research effort of Cytel Corporation, a biotechnology company in San Diego, California, USA, while continuing grant-funded research part-time. The third period began in 1999 when he moved to The Scripps Research Institute (TSRI). At this time, the NIGMS announced the glue grants. "The glycobiology community was looking for someone to lead the effort, and

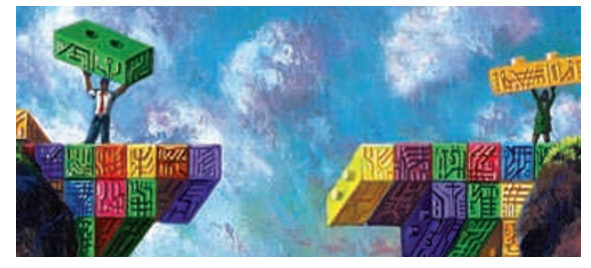

as I was in the early stages of building a lab at TSRI, I had the time to take it on. Because I had previously been in academia and had 10 years management training in biotech, I brought a skill set that was well suited to lead the large project envisioned by the glue grant."

To this day, Paulson continues to juggle his roles as, besides directing the CFG, he still holds his position as Professor of Chemical Physiology at TSRI. He finds working with individuals that have key roles in the CFG particularly rewarding, and greatly enjoys seeing first-hand the impact the Consortium's work is having in the field of glycobiology.

He attributes the Consortium's success, reflected by its continuous growth and output, to strong leadership from the Steering Committee, setting a clear vision of how the databases and scientific cores would serve the CFG and its participating investigators, as well as the enthusiasm and engagement of the participating scientists. "The primary challenge facing us now is to meet the expectations of NIGMS for succeeding in the enterprise, and to determine how the CFG will continue when glue grant funding ends in 1.5 years."

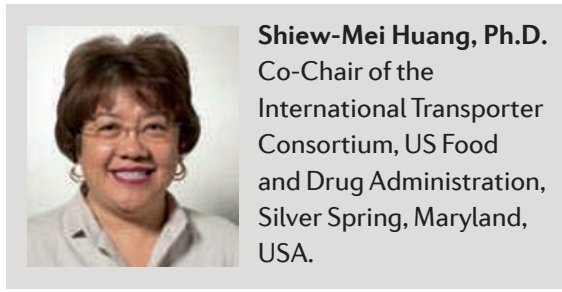

The International Transporter Consortium (ITC) was formed in 2007 as a result of recent advances in the field of membrane transporters and the US Food and Drug Administration (FDA) Critical Path Initiative (Clin. Pharmacol. Ther. 87, 32-36; 2010). The ITC brings together scientists representing all sectors of drug discovery, development and regulatory approval, who have an interest in the role of membrane transporters in therapeutic and adverse drug responses.

"One of the ITC's main goals is to provide comprehensive scientific recommendations for studies of transporter-related drug interactions in the development of new medical products," says Shiew-Mei Huang, a co-Chair of the ITC. Such recommendations are generally intended to support clinical development (Nature Rev. Drug Discov. 9, 215-236; 2010). The ITC also provides the FDA with an opportunity to hear collective concerns on drug development issues first-hand.

Huang's interest in drug development began during her Ph.D. studies at the University of Illinois, Chicago, USA, where she evaluated the kinetics of the antihistamine chlorpheniramine in animal models and in humans. Following her doctorate, Huang spent 8 years at a subsidiary of Johnson and Johnson called Ortho Pharmaceutical Company, now known as the Robert Wood Johnson Pharmaceutical Research Institute. She then went on to work for DuPont Merck, where she moved into a senior management position.

In 1996, Huang joined the Office of Clinical Pharmacology (OCP) at the Center for Drug Evaluation and Research at the FDA, an office that has since grown from $\sim 30$ to 140 staff. As Deputy Director of the OCP and Chair of the FDA's Drug Development and Drug Interactions Working Group, Huang was invited to represent the FDA in the ITC.

Along with academia and industry representatives - Kathleen Giacomini and Donald Tweedie, respectively - Huang chairs monthly ITC meetings. Together they are responsible for deciding the scientific issues to discuss in the larger group setting. "The aim is to establish a dialogue among thought leaders so that they can form opinions and make informed decisions," says Huang. They also need to ensure that all sectors (academia, FDA and industry) and regions (United States, Europe and Asia) are well represented.

Huang greatly enjoys working with world-class reviewers at the FDA, and her involvement in the ITC has enabled her to work with experts in the drug transporter field and to keep up-to-date with the latest scientific data and tools that are available to address crucial issues related to drug transporters. "The most valuable experience is to continue to learn to work with others and realize that collaborations are key to success, not only for a team but also for individuals working with my co-Chairs in the Consortium I have learnt great leadership skills and am always inspired by the willingness of all the participants to contribute to a better understanding of important scientific issues in the drug development process."

WEB SITE

Career snapshots: http://www.nature.com/drugdisc/nj/ nj dd arch.html 